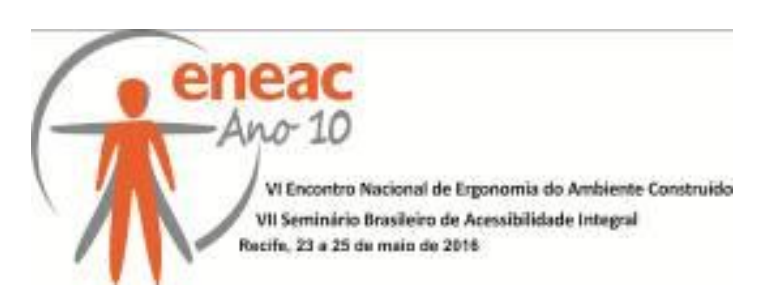

\title{
PARÂMETROS TÉCNICOS: ESTUDO COMPARATIVO DE CONDIÇÕES DE ACESSIBILIDADE NAS CIDADES DO PORTO E FORTALEZA
}

\author{
PINHO, Ana Carolina Noronha de (1); \\ SANTIAGO, Zilsa Maria Pinto (2) \\ (1) Faculdade de Desporto da Universidade do Porto, MsC. \\ e-mail: carolnoronhapinho@gmail.com \\ (2) Universidade Federal do Ceará, Dra. \\ e-mail: zilsa@arquitetura.ufc.br
}

\begin{abstract}
RESUMO
O presente artigo tem como objetivo apresentar uma análise comparativa, por intermédio de imagens, da acessibilidade e da mobilidade das vias de circulação nas cidades do Porto e de Fortaleza. O método utilizado foi a análise documental fotográfica através do processo comparativo de imagens. Os resultados refletiram que a acessibilidade demanda uma vigorosa reestruturação para melhoria e padronização das vias e dos espaços públicos de circulação em ambas as cidades. Concluímos que o acesso para os diferentes tipos de ambiente e pessoas requer um amplo incitamento de todos os grupos que compõem o convívio social visando o bem-estar comum.
\end{abstract}

Palavras chave: mobilidade; acessibilidade; espaço urbano; inclusão.

\begin{abstract}
This article aims to present a comparative analysis, through images, accessibility and mobility traffic routes in the cities of Porto and Fortaleza. The method used was the documentary photographic analysis through the comparative process. The results reflected that accessibility demands a vigorous restructuring for improvement and standardization of roads and public spaces of movement in both cities. We concluded that the access to the different types of environment and people requires a broad incitement of all the groups that make up the social conviviality to common well-being.
\end{abstract}

Keywords: mobility; accessibility; urban space; inclusion.

\section{INTRODUÇÃO}

Ao destacar o ambiente público e o seu planejamento com o intuito de promover, encorajar a independência e a autonomia das pessoas com deficiência, este fato, esbarra muitas vezes em alguns obstáculos que inviabilizam o livre acesso a serviços primordiais como cidadão, consequentemente, limita uma boa qualidade de vida.

Hanson (2004) descreve o termo "architectural disability" como forma de expressar o desenho físico, a distribuição física e a construção de edifícios e ambientes que limitam as pessoas com barreiras e a falta de segurança. Além disso, esta circunstância torna o ambiente urbano desconfortante, inoportuno e inseguro para a sua utilização por parte das 


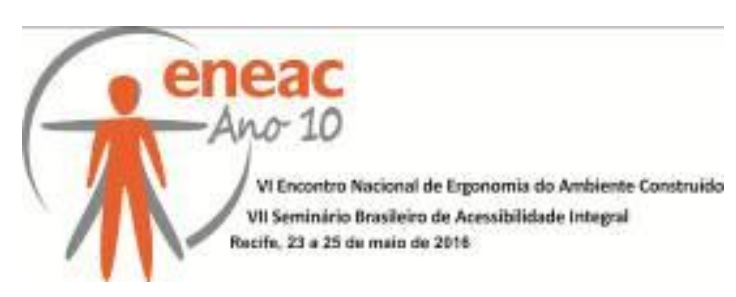

pessoas. Bromley, Matthews e Thomas (2007) também revela que as cidades ocidentais vão se desenvolvendo fisicamente com concepções e desenhos onde a forma edificada está inscrita nos valores da sociedade.

Essas observações da acessibilidade mostram que quando um espaço construído apresenta um obstáculo, por vezes impõe ao indivíduo com dificuldade de locomoção a se prostrar sobre uma condição segregada provinda do abandono do conceito decorrente de espaços e objetos inapropriadamente projetados para as pessoas "ditas normais".

Desta forma, é crucial construir ambientes onde todas as pessoas consideram-se incluídas, possibilitando a adaptação para todos os indivíduos, principalmente, aqueles que apresentam limitações funcionais. Um ambiente com espaços acessíveis, incluindo os princípios do Desenho Universal (DU), promove uma maior autonomia e independência para o desfrute dos espaços urbanos e das estruturas físicas para a universalização dos direitos das pessoas em suas mais diversas condições de mobilidade (ANDRADE, 1995; HANSON, 2004).

Além disso, é indispensável estimular a criação de soluções acessíveis e isso obriga a uma gestão planificada e consciente. Concomitantemente, ao congregar uma concepção universal na acessibilidade, expressa por um desenho feito à medida de todos, se faz necessário exigir orientações concretas e legais para que a promoção da acessibilidade seja efetuada de forma mais efetiva e rápida.

\section{OBJETIVO DO ESTUDO}

Ao observar os padrões de acessibilidade demasiadamente nos deparamos com o acesso público urbano obstruído ou limitado atingindo diretamente as pessoas com deficiência. É nessa perspectiva, portanto, que este artigo pretende apresentar uma análise comparativa, por intermédio de imagens, da acessibilidade e da mobilidade das vias de circulação nas cidades do Porto e de Fortaleza.

\section{METODOLOGIA}

A compreensão de cunho documental visual, como a fotografia, de acordo com Péquinot (2006, p.49), "sempre um jogo de realidade narrativa", desta maneira resume-se por "uma ferramenta de produção de conhecimento e de investigação da realidade".

Desta forma, o uso de fotos com a meta de aprofundar os relatos nas pesquisas procura investigar a realidade contada mais rica em detalhes e oportunizar a aproximação do pesquisador com o fenômeno estudado (OLIVEIRA; OLIVEIRA; FABRÍCIO, 2003).

Esta pesquisa, portanto, teve o caráter documental fotográfico ligado a parâmetros técnicos, escritos em Guias de Acessibilidade de ambas as cidades analisadas. Através do acesso ao acervo de imagens pessoais capturada, nas respectivas cidades visitadas, onde foi possível detalhar fotografias consideradas relevantes, no sentido de corroborar com este estudo exploratório.

Esta etapa iniciou-se ainda em 2012, quando foram iniciadas as visitas estratégicas às áreas de estudo, servindo de base para a elaboração de uma tabela comparativa. Estas visitas foram fundamentais à compreensão do problema.

O critério de seleção das fotografias utilizadas na pesquisa, todas foram obtidas a partir do registro digital in locu no decorrer de diversas visitas nos locais escolhidos para a análise comparativa, ambiental e estrutural da acessibilidade. As fotografias foram realizadas a 


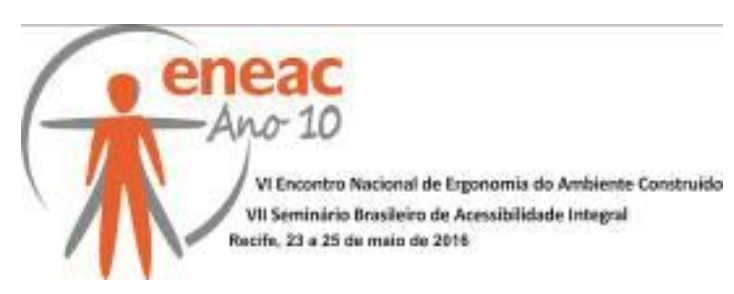

partir de processos tradicionais e convencionais de captura, ou seja, as imagens foram registradas por meio de uma máquina fotográfica digital, das marcas Sony® e Nikon®.

As imagens encontram-se inseridas pareadas na tabela sob a forma de registro numérico, título, fonte, parâmetros técnicos e referências técnicas. A partir desta utilização metodológica mostrada mais adiante na discussão dos resultados, a visualização e compreensão das imagens tornam-se pedagogicamente executável para o processo de avaliação da pesquisa.

\section{RESULTADOS E DISCUSSÃO}

O procedimento metodológico apresentado neste artigo consta da análise documental fotográfica das cidades do Porto e de Fortaleza, que foram analisadas e discutidas por intermédio dos parâmetros técnicos vigorados nos Guias de Acessibilidade de cada município.

A análise desempenhada através dos Guias municipais foi proposital devido à síntese técnica e o respeito aos quesitos normativos para tratar das questões sobre acessibilidade, de modo geral, nos espaços e edificações públicas de uso das pessoas com deficiência ou com alguma dificuldade de locomoção.

O critério de utilização e inclusão das imagens se deu mediante a comparação segmentada apenas entre bairros centrais e entre bairros adjacentes. Foram filtradas fotos que possuíssem aspectos críticos e visíveis quanto às questões da acessibilidade nas vias e espaços públicos da cidade do Porto e de Fortaleza.

A análise documental fotográfica da cidade do Porto foi realizada por meio de visitas aos seguintes bairros: Bonfim, Boavista, Bela Vista, Lapa e Cedofeita, de acordo com a ilustração da Figura 1.

\section{Figura 1 - Bairros visitados na cidade do Porto}

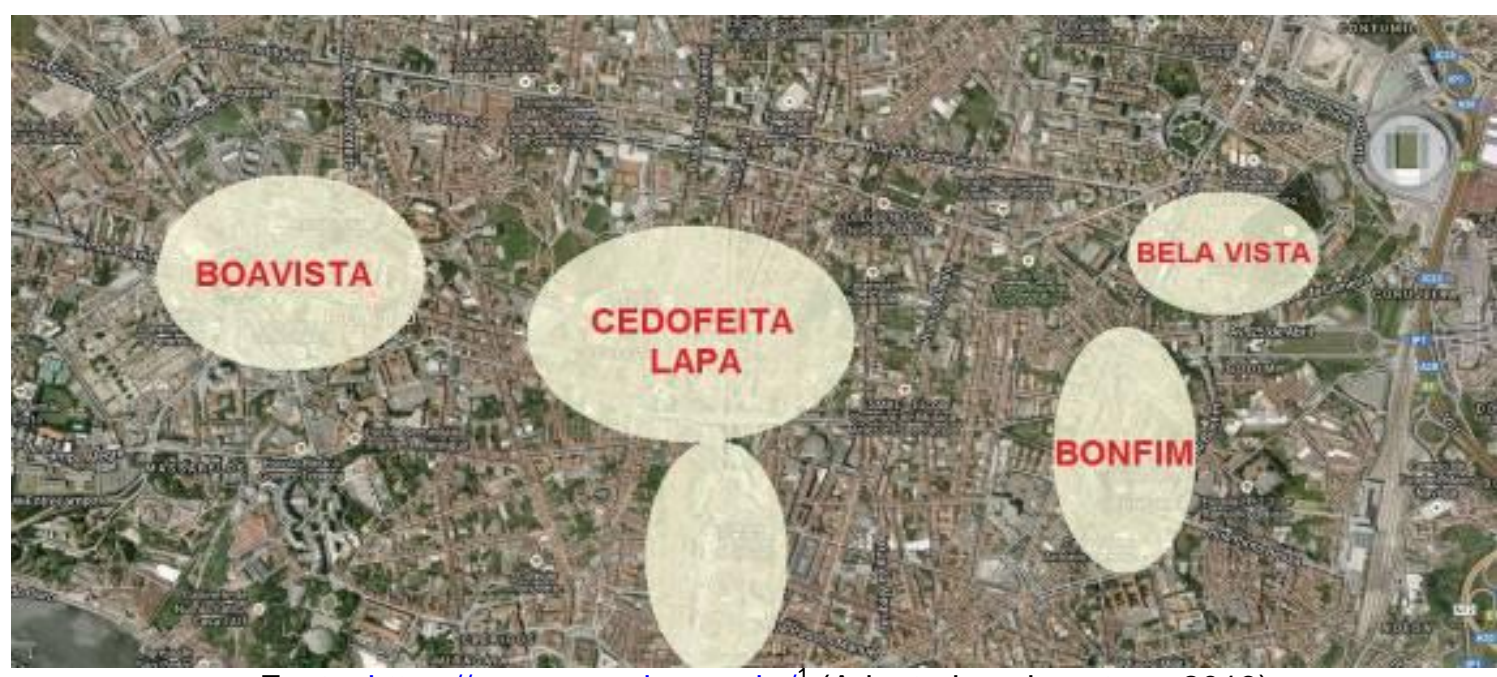

Fonte: https://maps.google.com.br/' (Adaptado pela autora, 2013) 


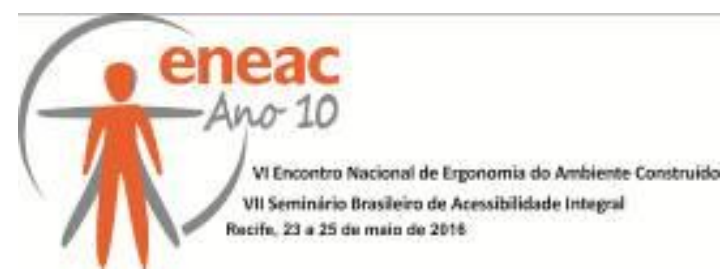

A análise documental fotográfica da cidade de Fortaleza foi realizada por meio de visitas ao Centro da cidade e aos bairros: Praia de Iracema e São Gerardo, conforme ilustra a Figura 2.

Figura 2 - Bairros visitados na cidade de Fortaleza

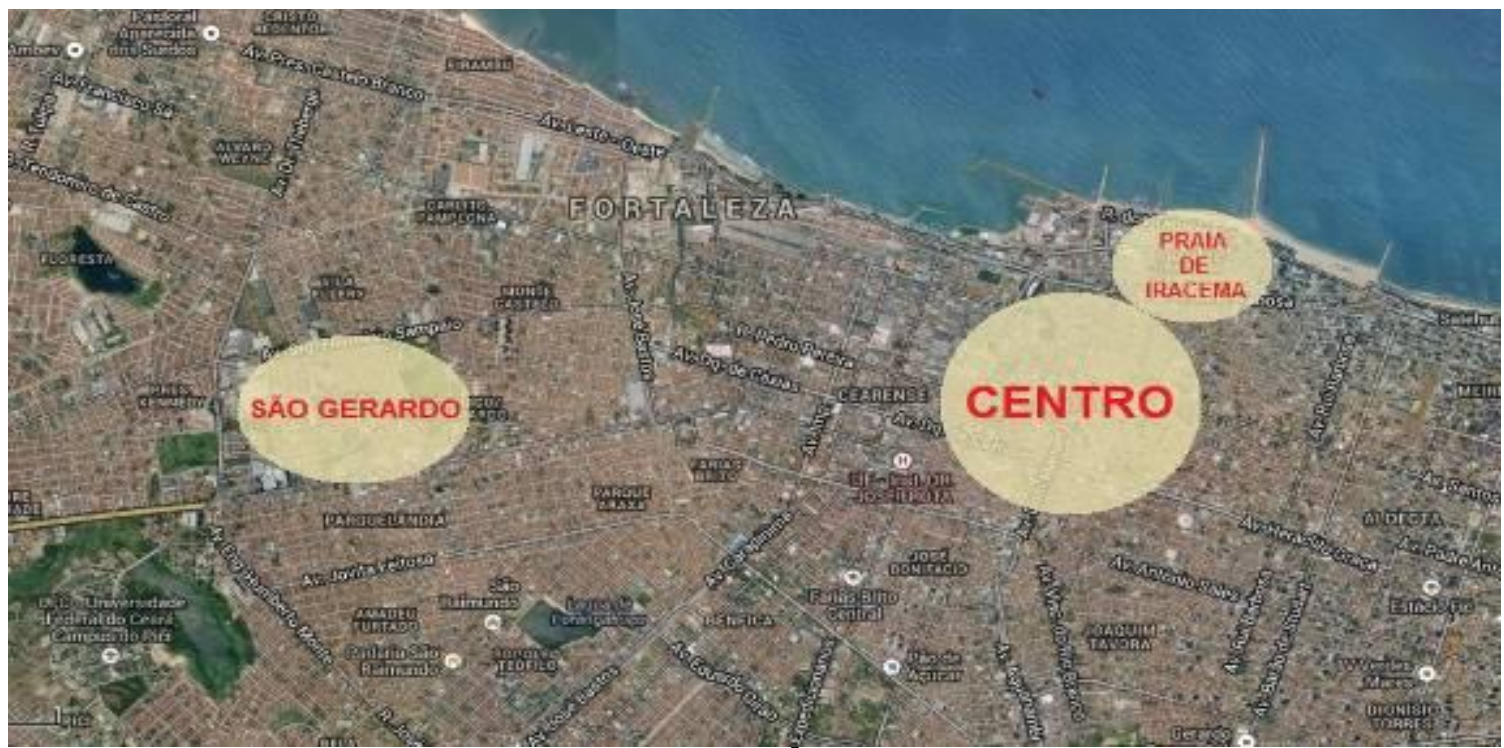

Fonte: $\underline{\text { https://maps.google.com.br/2 }}$ (Adaptado pela autora, 2013)

As imagens foram organizadas procurando-se fazer um paralelo de situações nas duas cidades de forma a constituir uma compreensão didática para o estudo. Conforme se apresenta na Tabela 1.

Tabela 1 - Análise Fotográfica Exploratória

\begin{tabular}{|c|c|c|}
\hline & \\
Título & $\begin{array}{c}\text { Área de circulação com infraestrutura } \\
\text { privilegiada para pedestre na Praça da } \\
\text { Liberdade, Aliados (2012) }\end{array}$ & $\begin{array}{c}\text { Área de circulação com } \\
\text { infraestrutura privilegiada para } \\
\text { pedestre na Praça do Ferreira, } \\
\text { Centro (2013) }\end{array}$ \\
\hline Registro $\mathrm{n} . \mathrm{o}$ & Porto 01 & Fortaleza 01 \\
\hline Fonte & A Autora & A Autora \\
\hline
\end{tabular}




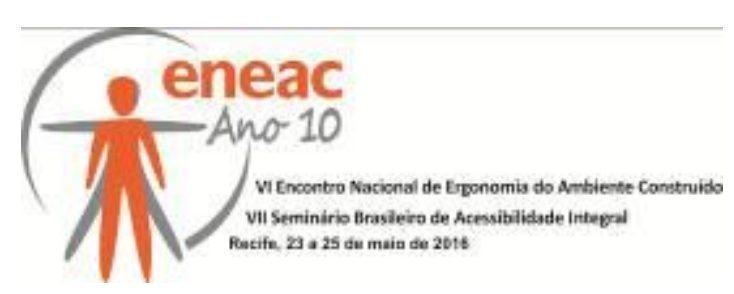

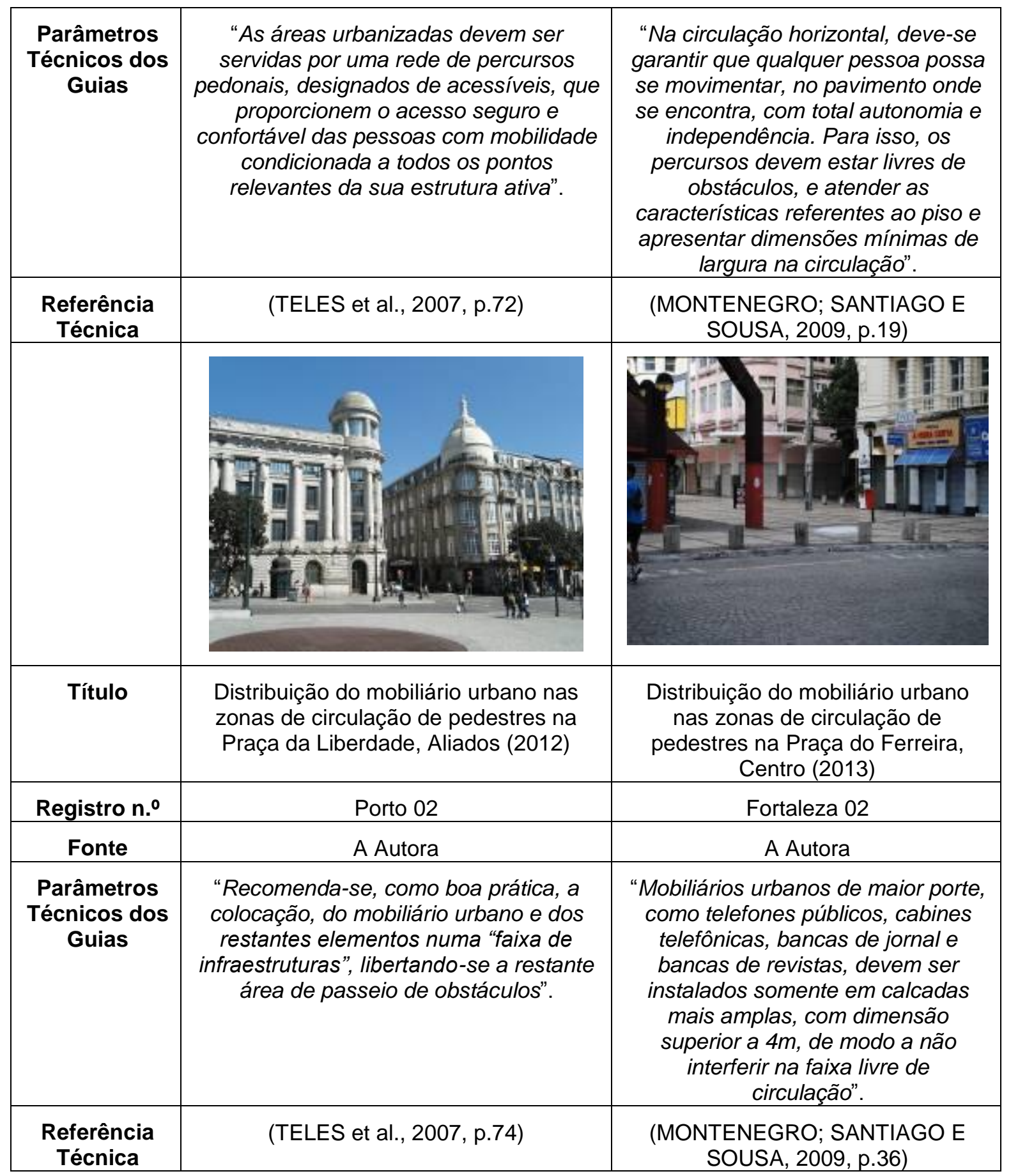




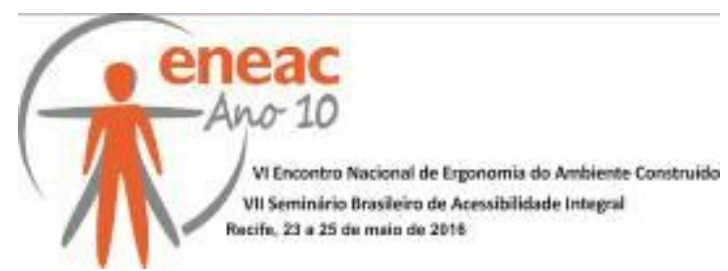

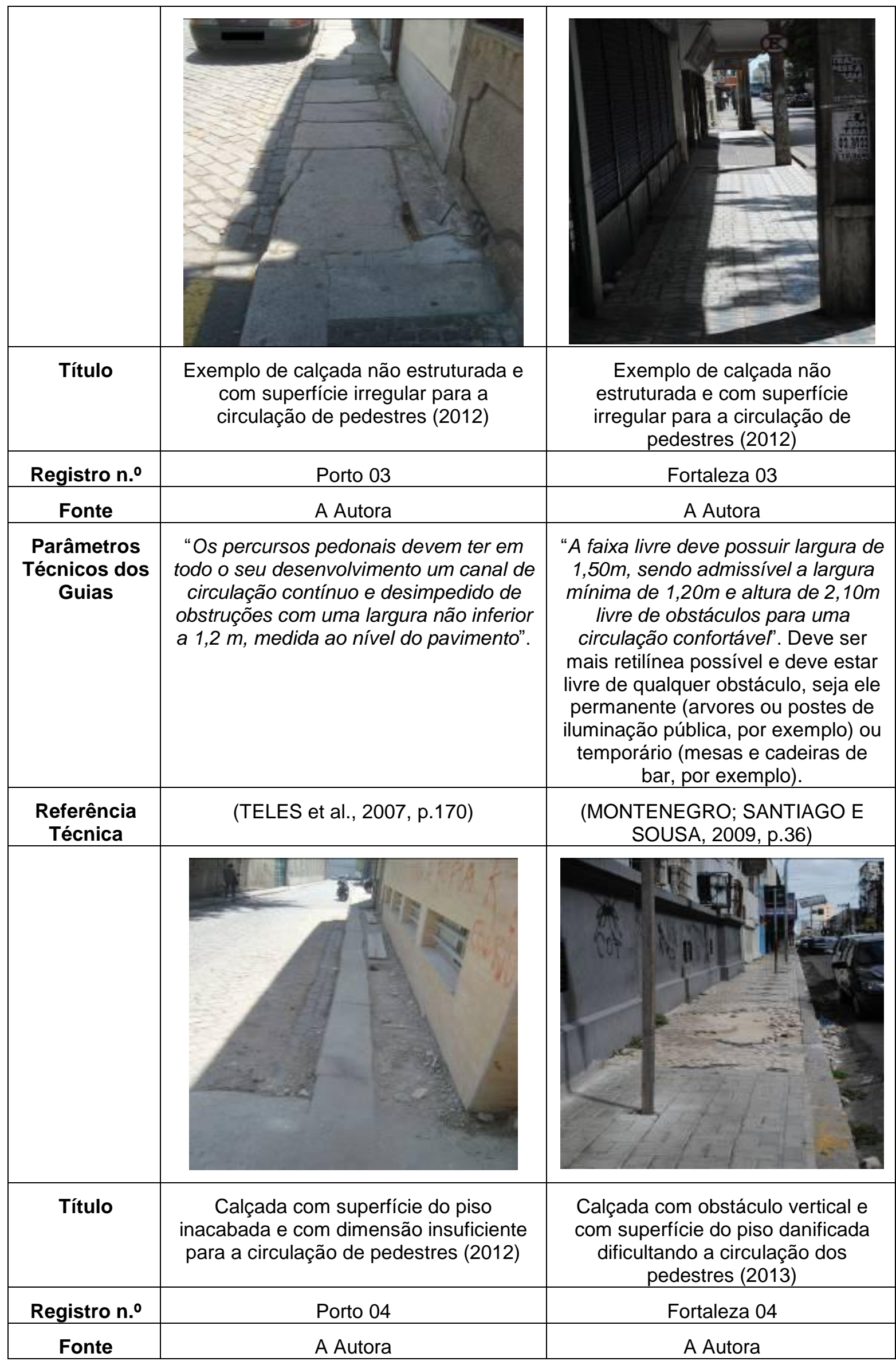




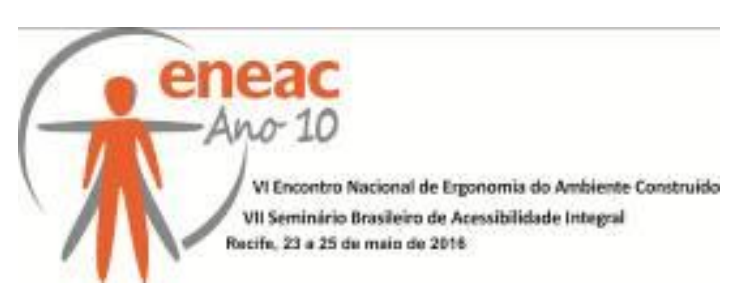

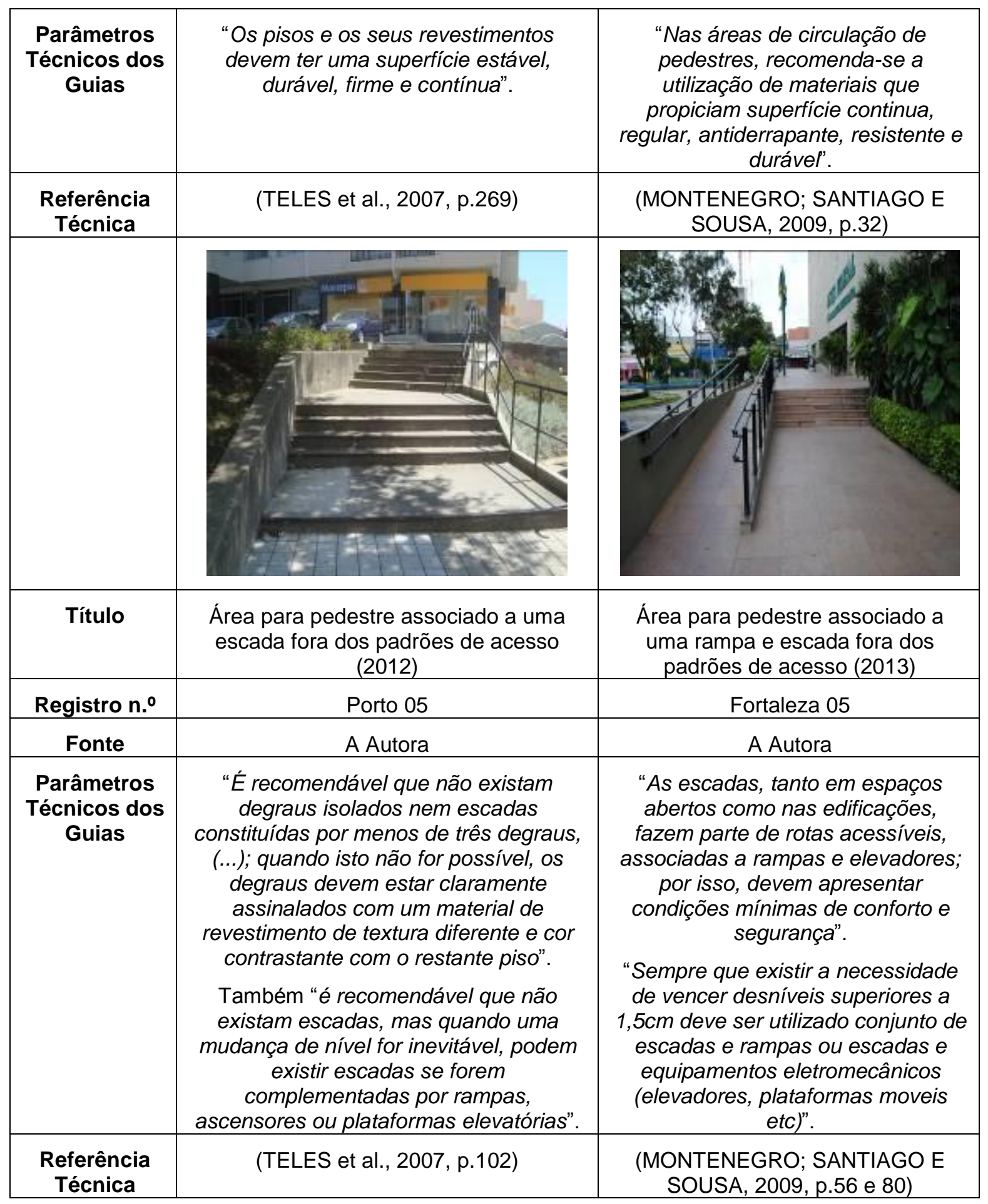




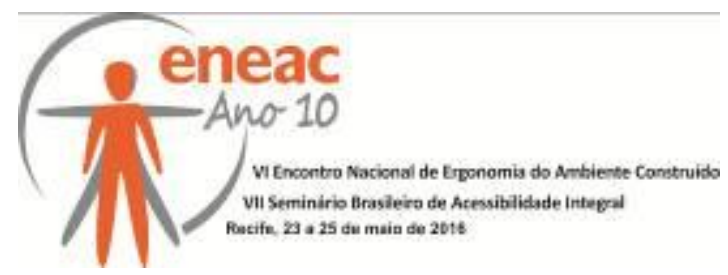

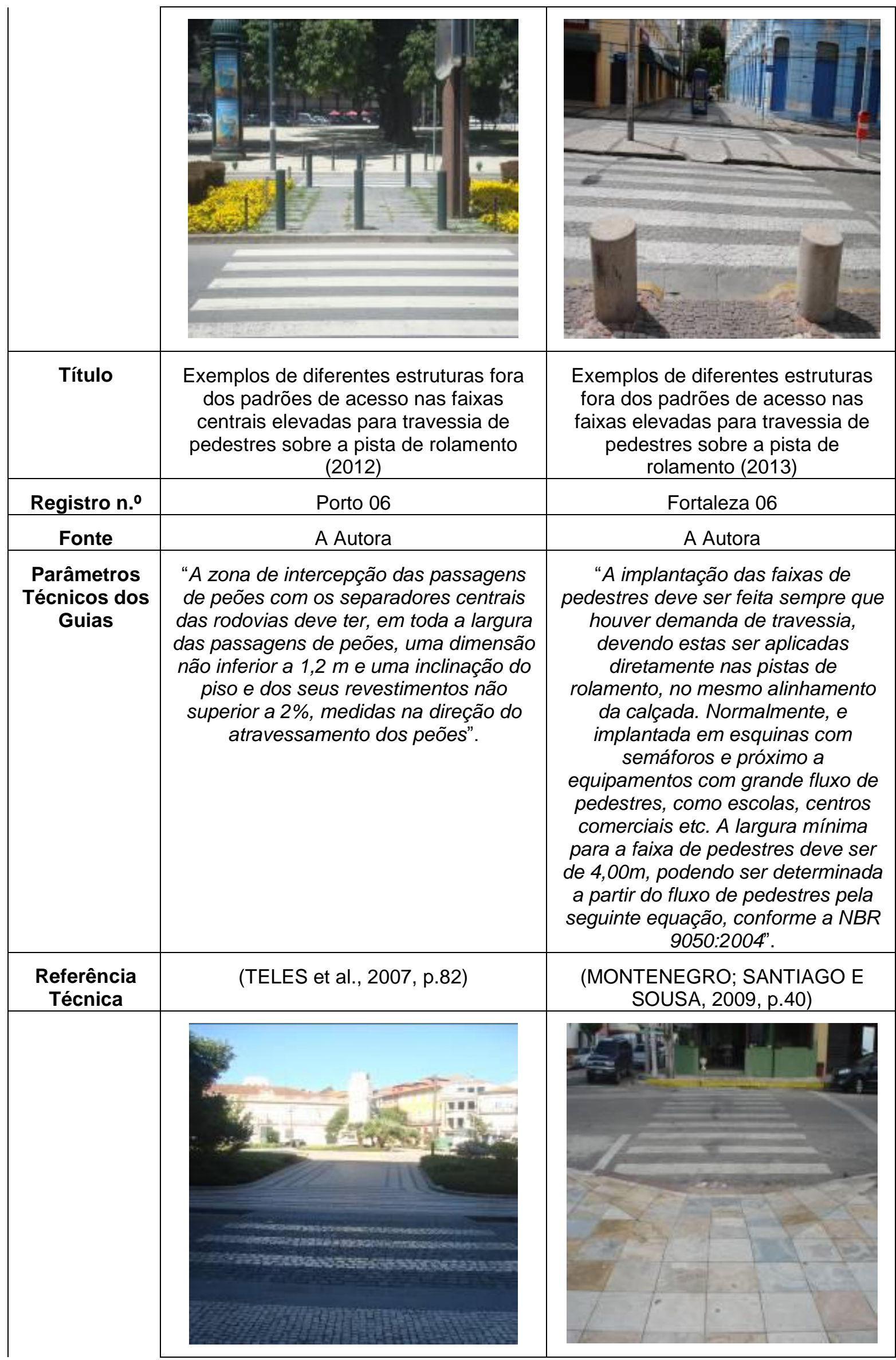




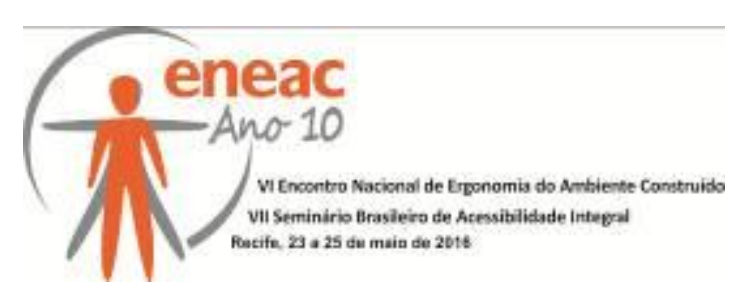

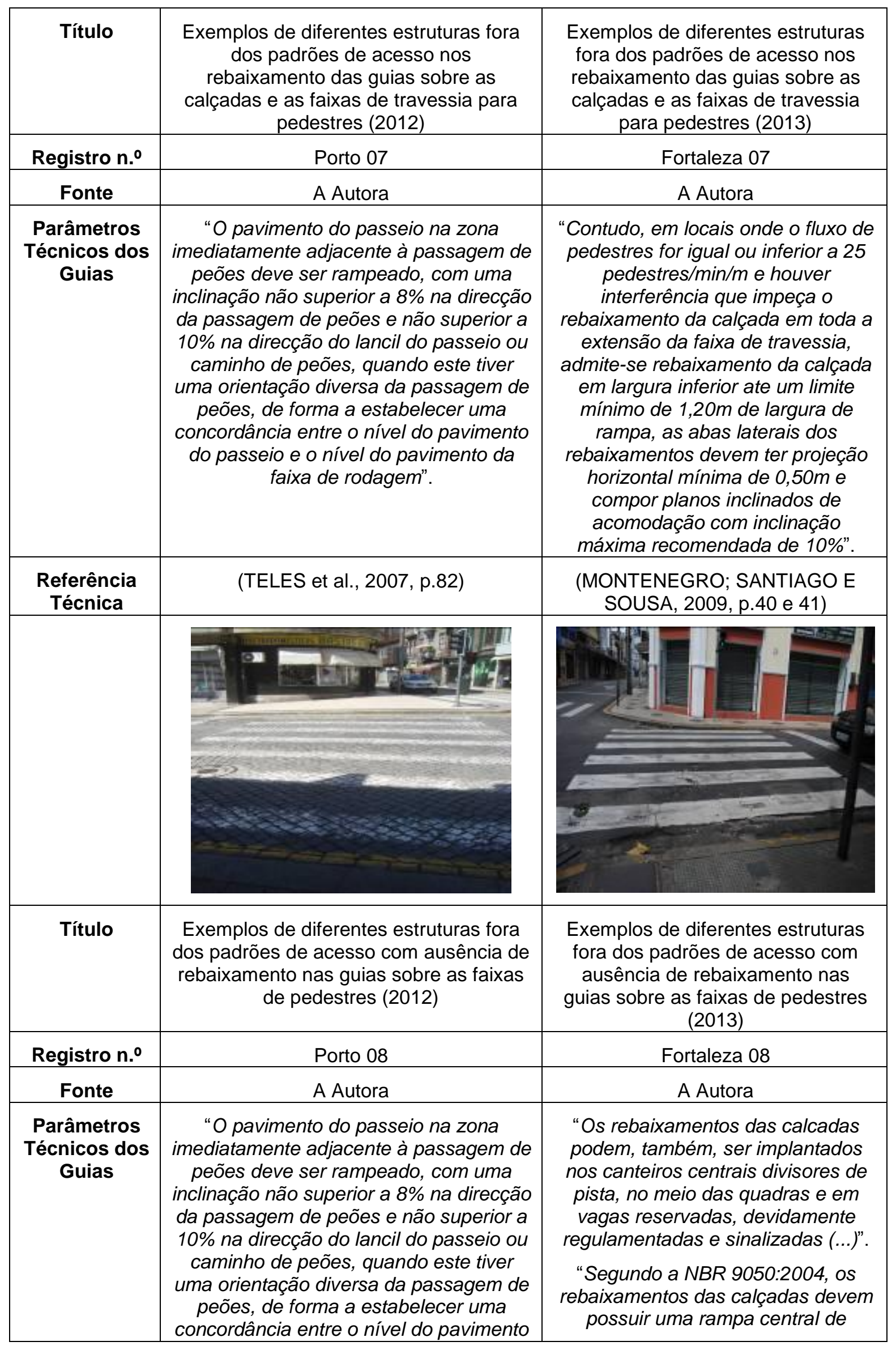




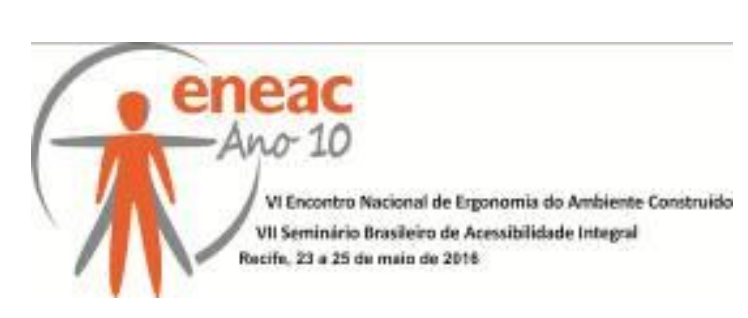

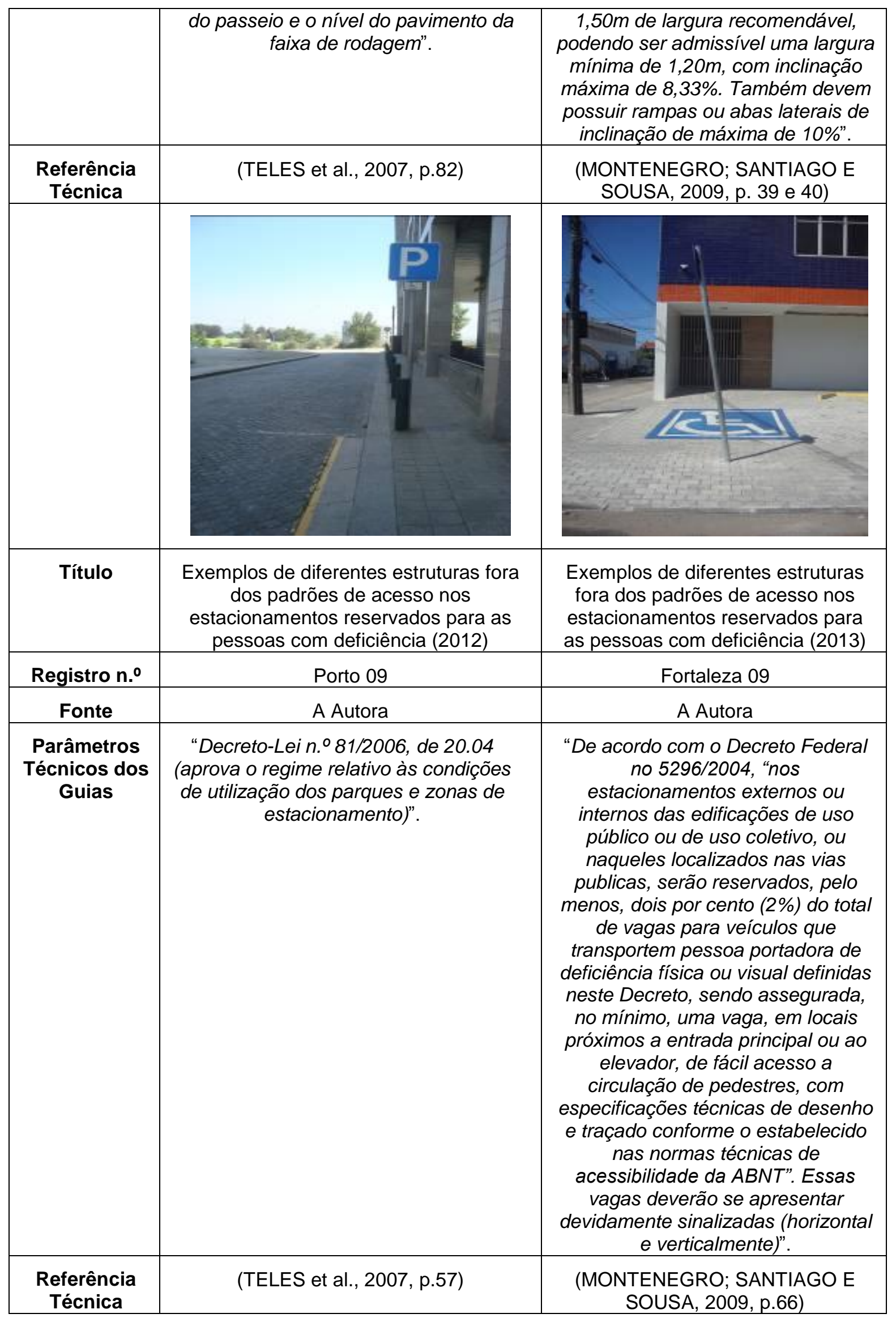




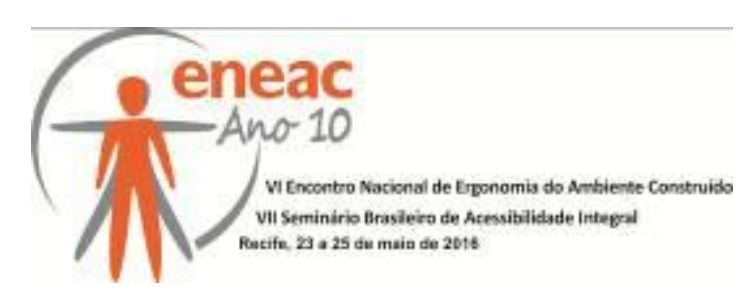

Por meio de uma visão holística das imagens referidas acima é entendido que a acessibilidade nas vias públicas de circulação nas cidades do Porto e de Fortaleza apresenta algumas semelhanças. Aponta para uma demanda de uma maior intervenção para a melhoria e padronização das vias públicas de circulação, pois é notório que essas vias possuem déficit estrutural com barreiras físicas que podem dificultar o livre acesso e circulação dos seus usuários.

Os guias são ferramentas fundamentais para o conhecimento público. Estes guias contribuem de forma significativa para a orientação e aperfeiçoamento da mobilidade urbana, se assim forem considerados por todos, principalmente pelos gestores municipais. No desafio de estruturar ou mesmo adequar uma cidade, requer um trabalho profissional multidisciplinar no sentido de buscar soluções afetas às questões que envolvem a acessibilidade física que contemplem, ao máximo, condições favoráveis a todas as pessoas, com ou sem deficiência de locomoção, de forma que estas também se sintam incluídas. Desse modo, atualmente, é inconcebível que edificações e obras públicas continuem sendo construídas ou reformadas sem considerar os princípios do desenho universal.

Nesta conjuntura, percebe-se a importância de pesquisas que apontam medidas qualitativas para avaliar a experiência e a qualidade do caminhar nos espaços públicos. Por outro lado, não existe uma única abordagem firmada estabelecida, como, por exemplo, temos Replogle (1990) que estudou fatores como existência de calçadas, abrigos em pontos de ônibus, o recuo de edificações e o tipo de uso do solo. Já Holtzclaw (1994) ratifica os fatores como continuidade das vias, existência de calçadas, recuo dos edifícios, velocidade do tráfego de veículos na via adjacente às calçadas e topografia. Dixon (1996) corrobora considerando os fatores determinantes na existência de calçadas, continuidade e largura das calçadas, conflitos de pedestres com veículos, amenidades existentes nas calçadas, nível de serviço para veículos na via, estado de conservação das calçadas e existência de medidas de moderação do tráfego.

Com embasamento nos trabalhos relatados acima, é notório perceber que todos empregam como parâmetros (critérios) a serem avaliados, dados referentes à caracterização física que influenciem a qualidade dos deslocamentos de pessoas com deficiência ou com restrições de mobilidade. Verifica-se, portanto, que, em se tratando de pessoas que demandam uma atenção especial, é importante frisar a condição de "possibilidade" de deslocamento por um caminho, que, embora se almeje da forma como define a NBR 9050/2004, com segurança, conforto e autonomia, nem sempre se encontra uma um caminho acessível atrativo ou confortável.

Esta condição, apesar de básica, muitas vezes não é garantida. As discussões que apresentamos foram intencionais a fim de adotar dados de caracterização física, fluidez, conforto, segurança e qualidade dos espaços que possam influenciar na acessibilidade dos espaços e vias públicas de circulação, bem como a mobilidade dos grupos de pedestres avaliados.

\section{CONCLUSÃO}

Investir em acessibilidade é oportunizar, é estimular a inclusão social e os direitos de ir e vir do cidadão. Organizar amplamente as disparidades antropométricas é permitir que pessoas de diversas características ou em diferentes situações possam interagir sem restrições com o ambiente construído. 


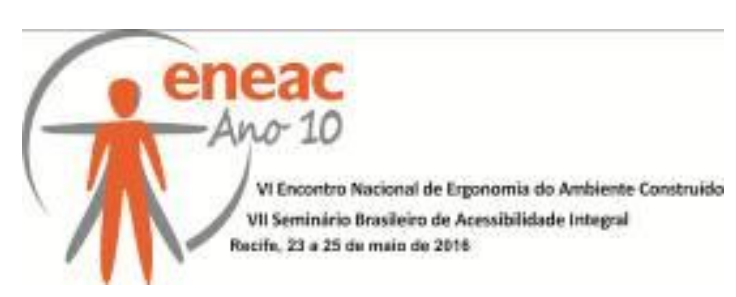

Concluímos que as imagens exploradas refletem, em parte, que a acessibilidade nos espaços públicos urbanos das cidades do Porto e de Fortaleza, demanda uma vigorosa reestruturação para melhoria e padronização das vias e dos espaços públicos de circulação.

Considera-se também que os guias são ferramentas significativas de âmbito público, sendo ferramentas importantes na orientação e aperfeiçoamento da mobilidade urbana.

O registro fotográfico, todavia, foi extremamente valioso, pois são as fotos que notificam as dificuldades existentes nas cidades estudadas e, assim, apresenta a necessidade de uma logística de como enfrentar as barreiras sociais, físicas e atitudinais no dia após dia de todos.

\section{REFERÊNCIAS BIBLIOGRÁFICAS}

Acesso em: 27 agosto 2013, disponível em<https://maps.google.com.br/> ${ }^{1}$ Acesso em: 27 agosto 2013, disponível em<https://maps.google.com.br/ $>^{2}$

ANDRADE, C. R. A morte do lugar público. 1995. Dissertação (Mestrado em Desenvolvimento Urbano e Regional) - Pós-graduação e Pesquisa em Planejamento Urbano e Regional, Universidade Federal de Pernambuco, 1995.

BROMLEY, R., MATTHEWS, D., \& THOMAS, C.. City centre accessibility for wheelchair users. Cities, v. 24, n. 3, p. 229-241. 2007.

DIXON, L. B. Bicycle and Pedestrian Level of Service Performance Measures and Standards for Congestion Management Systems. In: TRB Annual Meeting, 1996. Disponível em:< http://trb.metapress.com/content/36g783p825832850/fulltext.pdf>. Acesso em: 10 julho 2013.

HANSON, J. The Inclusive City: delivering a more accessible urban environment through inclusive design. 2004. Disponível em:<http://eprints.ucl.ac.uk/3351/>. Acesso em: 3 maio 2013.

HOLTZCLAW, J. Using Residencial Patterns and Transit to Decrease Auto Dependence and Costs. Smart Growth Network Web Site. 1994. Disponível em:<http://www.smartgrowth.org/library/cheers.html>. Acesso em: 23 julho 2013.

MONTENEGRO, N., SANTIAGO, Z., \& SOUSA, V. Guia de Acessibilidade: Espaço Público e Edificações, Secretaria da Infraestrutura do Estado do Ceará. SEINFRA, Fortaleza, 2009.

Oliveira,V., M. F.; Oliveira, V., F., \& Fabrício, L., E., O. (2003). Imagens na pesquisa com professores: o oral e a fotografia. Educar, Curitiba: Editora UFPR.

PÉQUINOT, B. De l'usage des images en sciences sociales. Communications, 2006.

REPLOGLE, M. Computer Transportation Models for Land Use Regulation and Master Planning in Montgomery County, Maryland. Transportation Research Record, p. 91-100. 1990. Disponível em:<http://www.inro.ca/en/pres_pap/european/eeug92/Europe02_1992.pdf>. Acesso em: 10 julho 2013.

Teles, P, et al. Guia de acessibilidade e mobilidade para todos. Secretariado Nacional de Reabilitação e Integração das Pessoas com Deficiência. Porto: Inova, 2007. 